\title{
The Future Comes Early for Medical Educators
}

\author{
Daniel J. Minter, $M D^{7}$, Rabih Geha, $\mathrm{MD}^{1,2}$, Reza Manesh, $M D^{3}$, and Gurpreet Dhaliwal, \\ $M D^{1,2}$
}

'Department of Medicine, University of California, San Francisco San Francisco, CA, USA; ${ }^{2}$ Medical Service, San Francisco VA Medical Center San Francisco, CA, USA; ${ }^{3}$ Division of Hospital Medicine, Northwestern University Feinberg School of Medicine Chicago, IL, USA.

\begin{abstract}
Many experts have foretold of a digital transformation in medical education. Yet, until recently, day-to-day practices for frontline clinician-educators, who cherish close physical and intellectual contact between the patient, learner, and teacher, have remained largely unchanged. The COVID-19 pandemic disrupted that model and is forcing teachers to pursue new ways to reach learners. We provide a roadmap for educators to start their transformation from an analog to a digital approach by harnessing existing tools including podcasts, social media, and videoconferencing. Teachers will need to enhance the same pedagogical and interpersonal practices that underpin effective in-person education while they learn new skills as they become curators, creators, and moderators in the digital space. This adaptation is essential, as many of the changes in medical education spurred by COVID-19 will likely far outlast the pandemic.
\end{abstract}

J Gen Intern Med 36(5):1400-3

DOI: $10.1007 / \mathrm{s} 11606-020-06128-y$

(C) Society of General Internal Medicine 2020

\section{INTRODUCTION}

For over a decade, expert panels, outside observers, and forward-thinking educators have foretold of a transformation in medical education from physical spaces to a digital existence. ${ }^{1-4}$ Yet, the day-to-day practices of the clinicianeducator have not changed radically, with most of us still following and cherishing the cognitive apprenticeship model of close physical and intellectual interaction between the patient, learner, and teacher. The COVID-19 pandemic, with social distancing and suspension of many in-person exchanges, brought this familiar approach to a halt. Frontline clinician-educators who did not have to grapple with the projected future in medical education are coming to terms with a new realization: the future is here.

COVID-19 has not brought a radical revolution where big data, artificial intelligence, or virtual reality is the currency of the clinician educator, but it has catalyzed an evolution where

Electronic supplementary material The online version of this article (https://doi.org/10.1007/s11606-020-06128-y) contains supplementary material, which is available to authorized users.

Received June 9, 2020

Revised July 31, 2020

Accepted August 10, 2020

Published online September 1, 2020 digital interfaces are moving from the margin to the mainstream of medical education. Many teachers who have made the necessary changes to their teaching to accommodate the physical and intellectual isolation of their learners are wondering what new skills should be permanently adopted for the future.

In this article, we discuss three roles that front-line clinicianeducators currently inhabit - those of curator, creator, and moderator - and how each can be adapted using digital tools (Table 1). To emphasize an evolution in current skills, we focused on roles that nearly all clinician-educators fulfill (as opposed to more specialized or novel roles). We selected tools (podcasts, social media, and videoconferencing) that have low barriers to entry (free, easy-to-use interfaces, modest technology requirements) for the teacher, are familiar to learners, and have established scholarship in the medical education literature. This article provides a roadmap for teachers to extend their analog skills and become curators, creators, and moderators of the digital space.

\section{EDUCATOR AS CURATOR}

Teachers have always served as essential intermediaries, connecting trainees to educational resources drawn from their own physical and mental libraries. Even as educators now openly learn from trainees about the ever-expanding volume of digital content (including blogs, apps, and videos), teachers still have an obligation to direct students to resources that are evidence-based, utilize modern educational principles, and are suitable for the learner's stage of development. Among the many options for digital learning that educators are familiar with, we highlight podcasts, with their popularity, portability, and high educational quality, as an accessible digital resource for the educator as curator. ${ }^{5}$

Medical podcasts have varied formats, including discussions with authors of journal articles, interviews with content experts, and clinical reasoning case discussions. ${ }^{6-10}$ Many podcast programs are structured as conversations that allow listeners to feel as if they are in the same room as the hosts and their guest experts and teachers. The collegiality, dialogue, and frequent questions and clarifications - with a healthy dose of levity - exemplify the educational and enriching discussions that characterize the best clinical learning environments. ${ }^{11,12}$ 
Table 1 Accelerating the Transformation from Analog to Digital Teaching

\begin{tabular}{|c|c|c|c|c|}
\hline $\begin{array}{l}\text { Teacher's } \\
\text { role }\end{array}$ & Analog setting & Digital setting & Shared best attributes/best practices & Teacher action steps \\
\hline Curator & Review articles & Podcasts & $\begin{array}{l}\text { - Concise summaries } \\
\text { - Translation of research to practice } \\
\text { - Focus on questions and confusing points } \\
\text { that arise in practice } \\
\text { - Infographics }\end{array}$ & $\begin{array}{l}\text { - Subscribe to } 2-3 \text { podcasts } \\
\text { - Share podcast episodes that cover recent } \\
\text { patient care topic with learners }\end{array}$ \\
\hline Creator & Classroom & Twitter & $\begin{array}{l}\text { - Concise explanations } \\
\text { - Interaction between novices and experts } \\
\text { - Multimedia }\end{array}$ & $\begin{array}{l}\text { - Create Twitter account } \\
\text { - Direct learners to high quality tweetorials and } \\
\text { chats } \\
\text { - Gradually move from observer to creator }\end{array}$ \\
\hline Moderator & $\begin{array}{l}\text { Conference } \\
\text { room }\end{array}$ & Videoconference & $\begin{array}{l}\text { - Authentic clinical cases } \\
\text { - Interactive } \\
\text { - Safe learning environment }\end{array}$ & $\begin{array}{l}\text { - Initiate on-line conferences } \\
\text { - Practice integrating all voices via audio, video, } \\
\text { and chat }\end{array}$ \\
\hline
\end{tabular}

Just like teachers have prided themselves on being able to recall "a great article," the teacher of the future readily brings to mind - and quickly shares - a great podcast. In our experience, the chance that learners will listen to a podcast episode texted to their phone eclipses the probability that they will read an article that has been emailed or handed out. Teachers have always been tasked with "keeping up with the literature" to help guide and inform learners. Podcasts are now part of the literature. Teachers can subscribe to a few podcasts relevant to their specialty (Appendix) and track new episodes with an eye towards sharing them as supplements to precepting and other patient care conversations. ${ }^{13}$ The "educator as curator" is a specialist in these digital educational materials and knows how to select, sequence, and recommend the right content at the right time.

\section{EDUCATOR AS CREATOR}

Teachers have always been creators. Their creativity comes in the form of clinical pearls, stories, and chalk talks they call upon or improvise in the moment for the learners who join them at the bedside. This moment of social distancing has forced teachers to move their canvas from the whiteboard to digital platforms like social media, which is rapidly becoming a new form of classroom.

Twitter is an important educational channel that connects learners and teachers. \#Medtwitter, the medical community on Twitter, features cases, articles, and tutorials ("tweetorials") that are developed by educators who are highly regarded in both the "Twitterverse" and academia. ${ }^{14,15}$ Social media also serves as a democratizing force where medical students often tweet directly to national figures and vice versa. Some medical societies and journals host Twitter chats where participants can communicate with their peers about clinical topics and post a question where the answer may reach thousands of followers rather than dozens of classroom attendees. The whiteboard and a tweet are both platforms for teachers to share their best educational content; the former is generally received with a polite reaction, while the latter can garner immediate feedback in form of likes, retweets, and comments (both appreciative and corrective) from learners and teachers across the world.

Many teachers have leveraged the multiplier effect of social media to contribute to the educator commons and garner academic credit. ${ }^{16}$ Not all teachers have an interest in distributing their work, but this core tenant of academics - to create and share - has taken on greater importance as learners have been displaced from the wards and classroom. To maintain impact as an "educator as creator" teachers can gradually move along the spectrum of engagement from "lurking" (observing only) to retweeting to commenting and, finally, to creating content (Appendix). ${ }^{17,18}$ Even the reluctant instructor who does not seek widespread attention will appreciate the familiar faces amongst her digital followers in this new classroom, where her local students are already looking for their favorite teachers.

\section{EDUCATOR AS MODERATOR}

In-person case conferences have always been a foundation of medical education because they allow trainees to construct meaning through observation of and feedback from peers and teachers (social learning). ${ }^{19}$ Despite the popularity and utility of asynchronous digital platforms like podcasts and social media, the affinity for real-time discussion with peers and teachers remains strong.

Case conferences with authentic clinical problems, dynamic discussions, and diverse expertise characterize the most effective versions of these open forums. But great learning conversations do not happen on their own - whether in the physical space or the digital space - they are often elevated by a skilled and experienced moderator. Videoconferences now dominate the educational landscape, testing the skills of teachers who need to plan, execute, and lead these conversations. As with in-person conferences, effective moderators of virtual conferences must be skilled at monitoring the accuracy of medical information, gauging the degree of understanding among 
learners, modulating the interactivity in the room, and ensuring a safe learning environment that invites inquiry and vulnerability. ${ }^{20}$ The digital space not only creates more opportunities to practice and expand these skills but also poses new challenges. For instance, as group sizes increase, only a small subset of the community speaks through the audio channel, so the facilitator must elevate and integrate the voices of the greater number and diversity of learners who participate through the chat function.

The "educator as moderator" must become versed in the tools of digital conversation (e.g., chat functions, screen shares, polls, breakout rooms) that were not possible or practical with their analog predecessors (Appendix). ${ }^{21}$ Additionally, moderators must contend with variable levels of digital fluency among participants and security issues (e.g., "Zoom bombing"). Just as bedside clinicians are rapidly adapting to telemedicine, teachers who are skilled in face-to-face discussions must now become adroit at virtual facilitation. During a time of social distancing, these conferences also do more than educate - they keep us connected.

\section{THE LEARNING SCIENCES}

The goal of all clinician-educators is maximizing trainees' learning and understanding so that they can recall and apply knowledge and skills in future clinical encounters. When selecting new tools (e.g., podcasts) or engaging in new skills (e.g., videoconference facilitation), teachers are obligated to employ evidence-based methodologies. Learning science is a multidisciplinary field (drawing on education, cognitive psychology, and neuroscience) that examines how the brain learns effectively and the instructional methods that optimize that process. ${ }^{22}$ The aforementioned digital tools are not only technological innovations but also pedagogical advancements that capitalize on many learning science principles, including dualcoding, spaced repetition, and retrieval practice.

Dual-coding refers to the use of multiple modalities (i.e., combination of text, visuals, and audio) to strengthen retention of new knowledge. Many podcasts supplement their audio content with written show notes, infographics, and instructional videos on their websites and then amplify these dual-coding strategies by promoting these supplementary materials on social media platforms.

Spaced repetition is an instructional design technique that deliberately reviews or revisits material over multiple time points instead of through one sustained exposure. ${ }^{23}$ Some podcasts optimize learning through the spacing effect by creating series that re-examine topics covered in prior episodes. Spaced repetition has organically arisen as a feature of The Clinical Problem Solvers "Virtual Morning Report." After this daily case conference, members of the \#medtwitter community send out the case summary and key learning points within 24 hours, thereby giving attendees the chance to revisit the diagnostic journey and most important lessons from the session.

Retrieval practice involves deliberately creating challenges that entail recall of previously acquired knowledge, which is more effortful and more effective than simple re-exposure to information. ${ }^{24,25}$ The Core IM podcast utilizes pre- and postpodcast quizzing to reinforce key concepts (and often includes queries related to previous podcasts for spaced repetition as well).

\section{CONCLUSION}

Sometimes crises accelerate the inevitable. The COVID-19 pandemic has catalyzed nascent trends in medical education and motivated teachers to increase their digital skills to keep serving learners who long ago shifted to the digital space for their own self-study. Three enduring roles of teachers - as curators, creators, and moderators - offer an entry point to the future while staying connected to our learners today.

Abrupt changes to educational practices can be exciting for some faculty but challenging for others. Reticence may emerge from concerns about job security, discomfort with reduced competence when acquiring new skills, and questions of identity and purpose as an educator. ${ }^{26}$ Teachers may benefit from faculty development programs, informal support networks, and peer champions that reinforce the development of new skills.

These new approaches are an evolution (not revolution) in the core educator skill set. Although we are moving towards technological solutions in the face of a public health crisis, it remains the interpersonal elements - community, interactivity, and participation - that define great teaching, even in the digital world. Although predicting the future is perilous, one conclusion seems clear: many changes in medical education spurred by COVID-19 will far outlast the pandemic itself.

Corresponding Author: Daniel J. Minter, MD; Department of Medicine, University of California, San Francisco San Francisco, CA, USA (e-mail: Daniel.Minter@ucsf.edu).

\section{Compliance with Ethical Standards:}

Conflict of Interest: Drs. Rabih Geha and Reza Manesh are the cofounders of The Clinical Problem Solvers, a non-profit organization. Drs. Daniel J. Minter and Gurpreet Dhaliwal have nothing to disclose.

\section{REFERENCES}

1. Emanuel EJ. The Inevitable Reimagining of Medical Education. JAMA. 2020. https://doi.org/10.1001/jama.2020.1227. [Epub ahead of print].

2. Simpson $\mathbf{D}$, Marcdante $\mathbf{K}$, Souza $\mathbf{K H}$, Anderson A, Holmboe E. Job Roles of the 2025 Medical Educator. J Grad Med Educ 2018;10(3):243246.

3. Sklar DP. Looking Ahead: Futures Planning for Medical Education. Acad Med 2019;94(10):1401-1403. 
4. Duval JF, Opas LM, Nasca TJ, Johnson PF, Weiss KB. Report of the SI2025 Task Force. J Grad Med Educ 2017;9(6 Suppl):11-57.

5. Mallin M, Schlein S, Doctor S, Stroud S, Dawson M, Fix M. A survey of the current utilization of asynchronous education among emergency medicine residents in the United States. Acad Med 2014;89(4):598-601.

6. Berk J, Trivedi SP, Watto M, Williams P, Centor R. Medical Education Podcasts: Where We Are and Questions Unanswered. J Gen Intern Med 2020. https://doi.org/10.1007/s11606-019-05606-2. [Epub ahead of print]

7. Duckworth S, Leung TI, O'Glasser A, Clark A. Listen and learn: A guide to podcasts for internists. SGIM Forum 2019;42(7).

8. Riddell J, Robins L, Brown A, Sherbino J, Lin M, Ilgen JS Independent and Interwoven: A Qualitative Exploration of Residents' Experiences With Educational Podcasts. Acad Med 2020;95(1):89-96.

9. Cho D, Cosimini M, Espinoza J. Podcasting in medical education: a review of the literature. Korean J Med Educ 2017;29(4):229-239.

10. Kaplan H, Verma D, Sargsyan Z. What Traditional Lectures Can Learn From Podcasts. J Grad Med Educ 2020;12(3):250-253.

11. Caverzagie KJ, Goldenberg MG, Hall JM. Psychology and learning: The role of the clinical learning environment. Med Teach 2019;41(4):375-379.

12. Nordquist $\mathbf{J}$, Hall $\mathbf{J}$, Caverzagie $\mathbf{K}$, et al. The clinical learning environment. Med Teach 2019;41(4):366-372

13. Ahn J, Inboriboon PC, Bond MC. Podcasts: Accessing, Choosing, Creating, and Disseminating Content. J Grad Med Educ 2016;8(3):435436.

14. Breu AC. Why Is a Cow? Curiosity, Tweetorials, and the Return to Why. N Engl J Med 2019;381(12):1097-1098.

15. Sterling M, Leung $\mathbf{P}$, Wright $\mathbf{D}$, Bishop TF. The Use of Social Media in Graduate Medical Education: A Systematic Review. Acad Med 2017;92(7):1043-1056.

16. Cabrera D, Vartabedian BS, Spinner RJ, Jordan BL, Aase LA, Timimi FK. More Than Likes and Tweets: Creating Social Media Portfolios for Academic Promotion and Tenure. J Grad Med Educ 2017;9(4):421-425.

17. Jaffe RC, O'Glasser AY, Brooks M, Chapman M, Breu AC, Wray CM. Your @Attending Will \#Tweet You Now: Using Twitter in Medica
Education. Acad Med 2020. https://doi.org/10.1097/ACM. 0000000000003314. [Epub ahead of print]

18. Melvin L, Chan T. Using Twitter in Clinical Education and Practice. J Grad Med Educ. 2014;6(3):581-582.

19. Torre DM, Daley BJ, Sebastian JL, Elnicki DM. Overview of current learning theories for medical educators. Am J Med. 2006;119(10):903907

20. Razack S, Philibert I. Inclusion in the clinical learning environment: Building the conditions for diverse human flourishing. Med Teach. 2019;41(4):380-384

21. MacLeod A, Cameron P, Kits O, Tummons J. Technologies of Exposure: Videoconferenced Distributed Medical Education as a Sociomaterial Practice. Acad Med. 2019;94(3):412-418.

22. Van Hoof $\mathbf{T} \boldsymbol{J}$, Doyle $\mathbf{T} \boldsymbol{J}$. Learning science as a potential new source of understanding and improvement for continuing education and continuing professional development. Med Teach. 2018;40(9):880-885.

23. Phillips JL, Heneka N, Bhattarai P, Fraser C, Shaw T. Effectiveness of the spaced education pedagogy for clinicians' continuing professional development: a systematic review. Med Educ. 2019;53(9):886-902.

24. Larsen DP, Butler AC, Roediger HL 3rd. Test-enhanced learning in medical education. Med Educ. 2008;42(10):959-966.

25. Green ML, Moeller JJ, Spak JM. Test-enhanced learning in health professions education: A systematic review: BEME Guide No. 48. Med Teach. 2018;40(4):337-350.

26. Simpson D, Marcdante K, Souza KH. The Power of Peers: Faculty Development for Medical Educators of the Future. J Grad Med Educ. 2019;11(5):509-512

Publisher's Note: Springer Nature remains neutral with regard to jurisdictional claims in published maps and institutional affiliations. 